\title{
EFFECTS OF $\alpha$-AMINOOXYACETIC ACID ON THE LEVEL OF POLYAMINES, ANTHOCYANINS AND PHOTOSYNTHETIC PIGMENTS IN SEEDLINGS OF COMMON BUCKWHEAT (FAGOPYRUM ESCULENTUM MOENCH)
}

\author{
MARCIN HORBOWICZ ${ }^{1}$, RYSZARD KOSSON ${ }^{2}$, \\ DANUTA KOCZKODAJ ${ }^{1}$, LESŁAW B. LAHUTA ${ }^{3}$ \\ ${ }^{1}$ Siedlce University, Institute of Biology, \\ Department of Plant Physiology and Genetics \\ Prusa 12, 08-100 Siedlce, Poland \\ e-mail: mhorbowicz@uph.edu.pl \\ ${ }^{2}$ Research Institute of Horticulture \\ Konstytucji 3 Maja 1/3, 96-100 Skierniewice, Poland \\ ${ }^{3}$ University of Warmia and Mazury, \\ Department of Plant Physiology and Biotechnology \\ 10-719 Olsztyn, Oczapowskiego 1A/103A, Poland
}

(Received: April 13, 2010. Accepted: September 27, 2010)

\begin{abstract}
The present paper discusses the effects of $\alpha$-aminooxyacetic acid (AOA) on contents of polyamines, anthocyanins, photosynthetic pigments and phenylalanine ammonia-lyase activity in seedlings of common buckwheat (Fagopyrum esculentum Moench). AOA clearly decreased light-induced formation of anthocyanins and inhibited PAL activity in buckwheat hypocotyls, although a slight stimulatory effect on anthocyanins content in buckwheat cotyledons was observed. AOA declined the contents of chlorophylls $a$ and $b$, and total carotenoids in buckwheat cotyledons. The results show that AOA inhibits phenylpropanoids biosynthesis in buckwheat hypocotyls, and suppress photosynthesis in cotyledons. Moreover, the experiments show that AOA enhances the level of free putrescine in hypocotyls and the level of spermidine in buckwheat cotyledons. AOA also diminished the content of putrescine in cotyledons, but did not affect its level in buckwheat hypocotyls. AOA also substantially declined the level of cadaverine in buckwheat cotyledons, and did not affect its content in hypocotyls. Differences in effect of AOA on anthocyanins and polyamines accumulation indicate various physiological roles of the compounds in buckwheat hypocotyls and cotyledons.
\end{abstract}

KEY WORDS: aminooxyacetic acid, anthocyanins, chlorophylls, common buckwheat, putrescine, spermidine.

\section{INTRODUCTION}

Compounds carrying aminooxy groups effectively inhibit ethylene synthesis in plants (Amrhein and Gödeke 1977; Amrhein and Wenker 1979; Chandran et al. 2007). $\alpha$-Aminooxyacetic acid (AOA) interferes with the conversion of $S$-adenosylmethionine (SAM) to 1-amino-cyclopropane-L-carboxylic acid, which is the precursor of ethylene biosynthesis (Boller et al. 1979). AOA also blocks the induction effect of ethylene on the activity of phenylalanine ammonia-lyase (PAL). Ethylene is a PAL activator and its effect has been studied in wounded tissues (Engelsma and van Bruggen 1971; Hyodo et al. 1993). In hypocotyls of common buckwheat AOA inhibited biosyn- thesis of anthocyanins by declining PAL activity (Amrhein 1979). Similarly, root-fed AOA decreased growth rate, accumulation of hydroxyphenolics, anthocyanins and chlorophyll, as well as PAL activity in soybean seedlings (Hoagland and Duke 1982).

Plant origin amines are cationic compounds that have been implicated in a wide variety of biological reactions, and especially take part in plant responses to diseases (Walters 2003). Polyamines are important factors in various plant processes, including regulation of gene expression, translation, cell proliferation, modulation of cell signaling, and membrane stabilization (Takahashi and Kakehi 2010). Polyamines are also involved in stress responses and diseases in plants, indicating their importance for plant 
survival (Bais and Ravishankar 2002; Kakkar and Sawhney 2002; Kusano et al. 2008; Liu et al. 2007). Although the polyamines are essential for normal growth, their precise role(s) in these processes remains not fully clear (Walters 2003; Handa and Mattoo 2010). In plants, polyamines have been localized in the cytoplasm, and in organelles such as vacuoles, mitochondria, and chloroplasts (Kumar et al. 1997). Polyamines (PAs), such as putrescine (Put), spermidine (Spd) and spermine (Spm) were predominantly found in eukaryotes (Cohen et al. 1984; Handa and Mattoo 2010).

PAs and ethylene appear to be involved in a number of physiological processes of plants. PAs are synthesized from arginine and ornithine by respective decarboxylases. The intermediate agmatine, synthesized from arginine, is converted to Put, which is further transformed to Spd and Spm by transfers of aminopropyl groups from decarboxylated $S$ -adenosylmethionine. Therefore, SAM is a common precursor for both PAs and ethylene (Martin-Tanguy 2001). The biochemical mechanisms which have been suggested to explain the biosynthetic relationships between the two pathways are: (i) competitive demand for a limited pool of common precursor (SAM), and (ii) feedback inhibition of enzyme action system in one pathway by the product(s) of the competing pathway (Serrano et al. 1991). However, significance of these mechanisms during the plant growth and development has not been demonstrated.

Exogenous PAs (putrescine, spermidine and spermine) stimulated growth of barley seedling in a similar mode to the ethylene biosynthesis inhibitors (Locke et al. 2000). It was found earlier that polyamines inhibited ethylene biosynthesis in apple fruit and tobacco leaves (Apelbaum et al. 1981). Conversely, ethylene suppressed PAs biosynthesis, acting mainly by inhibiting the activity of SAM decarboxylase in pea seedlings (Icekson et al. 1986). Thus, antagonism between synthesis of higher PAs and ethylene may exist, since they share the same intermediate. In general, biotic and abiotic stresses frequently result in formation of ethylene, and ethylene regulates senescence-related processes in plants. Polyamines are antagonistic to the ethylene activity and may delay or prevent senescence (Roberts et al. 1984). It is thought that anti-senescence activity of Put can be attributed to its ability to stabilize and protect membranes (Hong and Lee 1996). Other PAs like Spm and Spd seem to be more active in retarding senescence. Spm was more effective in preventing senescence-related events than similar treatments with other known senescence retardants (Apelbaum et al. 1981).

Ethylene has been shown to influence the biosynthesis of light-induced anthocyanin formation in plants (Craker et al. 1971; Cracker and Wetherbee 1973). In the case of sorghum tissue the rate of anthocyanin formation was dependent upon the time of ethylene treatment in relation to light exposure and the stage of the anthocyanins production (Craker et al. 1971).

Common buckwheat (Fagopyrum esculentum Moench) is dicotyledonous plant of high potential for pharmaceutical and nutraceutical possibilities. Many health claims exist for buckwheat; for example, that it can help people who suffer from high blood pressure, high cholesterol, and celiac disease. Buckwheat seed accumulates specific carbohydrates named fagopyritols, galactosides of D-chiro-inositol (Horbowicz et al. 1998; Horbowicz and Obendorf 2005).
The fagopyritols can help diabetics' patients respond to insulin (Kawa et al. 2003). Buckwheat hypocotyls provide a convenient model system for investigation of the role of anthocyanin and other compounds because has an inherently low capacity for light utilization due to lack of chlorophyll (Troyer 1964). Seedlings typically attain maximum pigmentation a few days after germination process therefore experiments are easy and quick to repeat. Seedlings of common buckwheat are considered as functional food due to their high nutritive value (Kim et al. 2004). The green sprouts of common buckwheat in Japan are popular as raw vegetables. They are sold either as fresh vegetable in supermarkets or as powder (Kim et al. 2006).

There is no information in available literature if inhibitory effect aminooxyacetic acid on ethylene and anthocyanins synthesis is accompanied by an impact on polyamines and photosynthetic pigments in plants. Therefore the purpose of our study was to determine whether AOA could modify particular free polyamines, in relation to changes of photosynthetic pigments and anthocyanin in seedlings of common buckwheat. The effect of exogenously applied ethylene, spermidine and/or putrescine on biosynthesis of anthocyanins was also investigated.

\section{MATERIALS AND METHODS}

\section{Plant material}

Seedlings of common buckwheat (Fagopyrum esculentum Moench) cv. Hruszowska were used in this study. Germination was carried out by placing buckwheat seeds between two layers of wet and rolled up filter paper as was described earlier (Horbowicz et al. 2008; Horbowicz et al. 2009). Roots were removed from the etiolated seedlings, and the upper parts (hypocotyl + cotyledons) were placed in the water solutions of AOA, Sigma $\left(10^{-3}\right.$ and $\left.10^{-4} \mathrm{M}\right)$. Seedlings incubated with AOA were kept for 4 days in air conditioned chamber, in which the temperature was maintained at $24 \pm 2{ }^{\circ} \mathrm{C} / 16 \pm 2{ }^{\circ} \mathrm{C}$ (day/night: $16 \mathrm{~h} / 8 \mathrm{~h}$ ). Light $\left(100 \mu \mathrm{Mol} \cdot \mathrm{m}^{-2} \cdot \mathrm{s}^{-1}\right)$ was provided by high-pressure sodium lamps.

In another experiment, four days old, etiolated buckwheat seedlings were treated with vapors of ethylene $\left(10^{-8}\right.$, $10^{-6}$ or $\left.10^{-4} \mathrm{M}\right)$ evolved from ethephon [(2-chloroethyl) phosphonic acid, Sigma] by solution of sodium hydroxide. The experiment was carried out in jars tightly capped with silicon membrane. Seedlings were kept for the next 4 days in conditioned chamber as described above.

In the next experiment the four days old, etiolated buckwheat seedlings were treated in the same conditions and duration (4 days) with $10^{-3} \mathrm{M}$ solution of putrescine or spermidine, to check their influence on anthocyanin accumulation.

\section{HPLC determination of polyamines}

Free PAs were analyzed according to procedures described earlier by Flores and Galston (1982). Briefly, plant tissues were homogenized in 5\% (v/v) perchloric acid in icecooled mortar. Plant homogenates were centrifuged, and in order to derivatize amines in supernatant benzoyl chloride was used for $45 \mathrm{~min}$ at $35^{\circ} \mathrm{C}$. Benzoyl derivatives were extracted by shaking the reaction mixture with ethyl acetate. The extraction was repeated twice, and pooled acetate 
TABLE 1. The effect of $\alpha$-aminooxyacetic acid (AOA) on content of chlorophylls and carotenoids in cotyledons, level of anthocyanins in cotyledons and hypocotyls, and PAL activity in hypocotyls of buckwheat seedlings. The significance of differences between means was calculated for all components separately, $\mathrm{p} \leq 0.05$, Newman-Keuls test. Different letters within the same column indicate statistically significant difference.

\begin{tabular}{lrr}
\hline & & \\
Analyzed component & & Treatment \\
\cline { 2 - 3 } & Control & AOA $10^{-4} \mathrm{M}$ \\
\hline Chlorophyll $a\left(\mu \mathrm{g} \cdot \mathrm{g}^{-1} \pm \mathrm{SD}\right)$ & $805 \pm 38 \mathrm{a}$ & $583 \pm 87 \mathrm{a}$ \\
Chlorophyll $b\left(\mu \mathrm{g} \cdot \mathrm{g}^{-1} \pm \mathrm{SD}\right)$ & $287 \pm 29 \mathrm{a}$ & $237 \pm 13 \mathrm{a}$ \\
Total carotenoids $\left(\mu \mathrm{g} \cdot \mathrm{g}^{-1} \pm \mathrm{SD}\right)$ & $168 \pm 7.2 \mathrm{a}$ & $185 \pm 13 \mathrm{a}$ \\
PAL activity in hypocotyls $\left(\mathrm{nmols} \cdot \mathrm{g}^{-1} \cdot \mathrm{h}^{-1} \pm \mathrm{SD}\right.$ of trans-cinnamic acid) & $0.71 \pm 0.13 \mathrm{a}$ & $96 \pm 12 \mathrm{~b}$ \\
Anthocyanins in hypocotyls $\left(\mu \mathrm{g} \cdot \mathrm{g}^{-1} \pm \mathrm{SD}\right)$ & $207.0 \pm 21.3 \mathrm{a}$ & $0.37 \pm 0.11 \mathrm{~b}$ \\
Anthocyanins in cotyledons $\left(\mu \mathrm{g} \cdot \mathrm{g}^{-1} \pm \mathrm{SD}\right)$ & $203.0 \pm 7.0$ & $153.7 \pm 8.6 \mathrm{~b}$ \\
\hline
\end{tabular}

layers were evaporated to dryness at $40^{\circ} \mathrm{C}$. The residue was dissolved in HPLC mobile phase (acetonitrile-water, 45: 55) and filtered through $0.46 \mu \mathrm{m}$ filter.

HPLC analysis was performed with Agilent liquid chromatograph (1200 Series). The mobile phase was mixture of acetonitrile-water $(45: 55, \mathrm{v} / \mathrm{v})$ at flow rate of $1.0 \mathrm{~mL} \cdot \mathrm{min}^{-1}$. Benzoylated amines were eluted isocratically at temperature $30^{\circ} \mathrm{C}$ using a RP column Eclipse $\mathrm{XDB}-\mathrm{C}_{18}$ analytical $(4.6 \times 150 \mathrm{~mm}, 5 \mu \mathrm{m}$ particle size $)$ and $\mathrm{C}_{18}$ guard column. The benzoyl PAs derivatives were detected at $245 \mathrm{~nm}$, DAD detector, and the content of amines was calculated from standard curves of commercially available standards.

\section{Determination of total anthocyanins}

Determination of total anthocyanins was carried out using the method described by Mancinelli (1984). Briefly, ten seedlings per one replicate were taken to analyses. Hypocotyl and cotyledon tissue was extracted separately with acidified $(1 \% \mathrm{HCl}, \mathrm{w} / \mathrm{v})$ methanol. Absorbance of the extracts was measured at $530 \mathrm{~nm}$ (anthocyanins) and 657 $\mathrm{nm}$ (absorbance of chlorophyll degradation products). The formula $\mathrm{A}_{530}-0.25 \mathrm{~A}_{657}$ was used to compensate for the absorption of chlorophyll degradation products at $530 \mathrm{~nm}$. Anthocyanins content was calculated as cyanidin-3-glucoside using 29600 as molecular extinction coefficient.

\section{Determination of photosynthetic pigments and PAL activity}

Chlorophyll a and $\mathrm{b}$, and total carotenoids contents in $80 \%$ acetone extracts of buckwheat cotyledons were quantified with spectrophotometer and extinction coefficient published by Lichtenthaler and Welburn (1983).

PAL activity in buckwheat hypocotyls was determined by monitoring of formation of trans-cinnamic acid (trans-CA) at $290 \mathrm{~nm}$, and $p$-hydroxycinnamic acid et $315 \mathrm{~nm}$ (Horbowicz et al. 2008). PAL activity in buckwheat hypocotyls was expressed as the sum of trans-CA and $p$-HCA (nmoles) produced during $1 \mathrm{~h}$ incubation by $1 \mathrm{~g}$ fresh plant tissue.

\section{Statistics}

The results presented in the Tables and figures are means of three replicates. Data were statistically examined by Newman-Keuls test. The different letters in figures and tables indicate significant differences between treatments with $\mathrm{p} \leq 0.05$ adopted as the criterion of significance.

\section{RESULTS}

Upon exposure to $\alpha$-aminooxyacetic acid (AOA), hypocotyls of etiolated buckwheat seedlings displayed reduced accumulation of anthocyanins in comparison to untreated control sample (Table 1). In case of high concentrated AOA $\left(10^{-3} \mathrm{M}\right)$ level of anthocyanins in buckwheat hypocotyls was almost four times lower than in control. However in case of buckwheat cotyledons some stimulatory effect was noted (Table 1). As shown in the table, the main reason for the decline of anthocyanins level in hypocotyl tissue is probably an inhibitory effect of AOA on PAL actvity. The PAL activity was almost three times lower in hypocotyls treated with AOA $10^{-3} \mathrm{M}$ AOA, than in control samples. AOA also declined the content of chlorophylls $a$ and $b$, and total carotenoids level in buckwheat cotyledons, although low concentration of the compound $\left(10^{-4} \mathrm{M}\right)$ had no significant effect on the pigments (Table 1).

Low concentration of ethylene $\left(10^{-8} \mathrm{M}\right.$ and $\left.10^{-6} \mathrm{M}\right)$ had no influence on content of anthocyanins in buckwheat hypocotyls but diminished its level in cotyledons (Table 2). High concentration of exogenous ethylene $\left(10^{-4} \mathrm{M}\right)$ caused slight stimulatory but not significant effect on anthocyanins accumulation in buckwheat hypocotyls, however further decline of its content was noted in cotyledons (Table 2).

TABLE 2. The effect of ethylene on total anthocyanins contents in hypocotyls and cotyledons of buckwheat seedlings. The significance of differences between means was calculated for hypocotyls and cotyledons separately, $p \leq 0.05$, Newman-Keuls test. Different letters within the same column indicate statistically significant difference.

\begin{tabular}{lcc}
\hline & Hypocotyls & Cotyledons \\
\cline { 2 - 3 } Treatment & \multicolumn{2}{c}{$\mu \mathrm{g} \cdot \mathrm{g}^{-1} \pm \mathrm{SD}$ fresh weight } \\
\hline Control & $212.9 \pm 1.9 \mathrm{~b}$ & $114.5 \pm 9.8 \mathrm{a}$ \\
Ethylene $10^{-8} \mathrm{M}$ & $189.9 \pm 9.2 \mathrm{~b}$ & $73.7 \pm 10.1 \mathrm{bc}$ \\
Ethylene $10^{-6} \mathrm{M}$ & $214.4 \pm 14.7 \mathrm{~b}$ & $59.6 \pm 9.9 \mathrm{c}$ \\
Ethylene $10^{-4} \mathrm{M}$ & $251.2 \pm 13.6 \mathrm{a}$ & $99.7 \pm 15.1 \mathrm{ab}$ \\
\hline
\end{tabular}

Among polyamines identified and measured in buckwheat seedlings, putrescine and spermidine were the major free amines (Table 3). In hypocotyls, putrescine content was about twice higher than that of spermidine, but in cotyledons the major polyamine was spermidine, the content of which was about two times higher than of putrescine. AOA significantly stimulated synthesis of putrescine in hypocotyls, and had only a slight effect on the synthesis of spermidine (Table 3). However, in case of cotyledons AOA enhanced the level of spermidine, and diminished the content of putrescine. Tryptamine and cadaverine were quantitatively minor polyamines found in buckwheat (Table 3). AOA substantially declined the level of cadaverine in buckwheat cotyledons, but did not affect its content in hypocotyls. Tryptamine was found in very low concen- 
TABLE 3. The effect of $\alpha$-aminooxyacetic acid (AOA) on amine content in hypocotyls and cotyledons of common buckwheat seedlings. The significance of differences between means was calculated for both polyamines in hypocotyls and cotyledons separately, $\mathrm{p} \leq 0.05$, NewmanKeuls test. Different letters within the same column indicate statistically significant difference. No letters means that the results were not significantly different. $\operatorname{tr}-$ traces

\begin{tabular}{lccc}
\hline & \multicolumn{3}{c}{ Treatment } \\
& Control & AOA $10^{-4} \mathrm{M}$ & AOA $10^{-3} \mathrm{M}$ \\
\cline { 2 - 4 } & & Hypocotyls \\
\hline Putrescine & $90.1 \pm 1.0 \mathrm{c}$ & $109.8 \pm 0.2 \mathrm{~b}$ & $123.6 \pm 0.3 \mathrm{a}$ \\
Spermidine & $46.2 \pm 5.9$ & $52.8 \pm 3.1$ & $54.7 \pm 3.8$ \\
Cadaverine & $2.4 \pm 0.7$ & $2.9 \pm 1.0$ & $2.4 \pm 0.3$ \\
Tryptamine & $2.3 \pm 0.4$ & $2.3 \pm 0.2$ & $\operatorname{tr}$ \\
\hline & & Cotyledons & \\
\hline Putrescine & $105.0 \pm 3.4 \mathrm{a}$ & $89.9 \pm 8.4 \mathrm{a}$ & $60.4 \pm 1.5 \mathrm{~b}$ \\
Spermidine & $215.1 \pm 12.2 \mathrm{~b}$ & $179.3 \pm 10.8 \mathrm{~b}$ & $288.7 \pm 9.0 \mathrm{a}$ \\
Cadaverine & $11.7 \pm 0.7 \mathrm{a}$ & $6.5 \pm 0.2 \mathrm{~b}$ & $2.4 \pm 0.9 \mathrm{c}$ \\
Tryptamine & $\operatorname{tr}$ & $\operatorname{tr}$ & $\operatorname{tr}$ \\
\hline
\end{tabular}

TABLE 4. The effect of spermidine and putrescine on total anthocyanins contents in hypocotyls and cotyledons of common buckwheat seedlings. The significance of differences between means was calculated for hypocotyls and cotyledons separately, $\mathrm{p} \leq 0.05$, Newman-Keuls test. Different letters within the same column indicate statistically significant difference. No letters means that the results were not significantly different.

\begin{tabular}{lcc}
\hline & Hypocotyls & Cotyledons \\
\cline { 2 - 3 } Treatment & $\mu \mathrm{g} \cdot \mathrm{g}^{-1} \pm$ SD fresh weight \\
\hline Control & $255 \pm 31$ & $448 \pm 58 \mathrm{a}$ \\
Spermidine, $10^{-3} \mathrm{M}$ & $313 \pm 25$ & $356 \pm 34 \mathrm{ab}$ \\
Putrescine, $10^{-3} \mathrm{M}$ & $317 \pm 22$ & $328 \pm 19 \mathrm{~b}$ \\
\hline
\end{tabular}

tration or in traces in buckwheat tissues, and its level was not changed as a result of AOA treatment.

Results shown in Table 4 show that exogenously applied spermidine and putrescine at concentration $10^{-3} \mathrm{M}$ slightly enhanced level of anthocyanins in buckwheat hypocotyls, however the effect was not significant. The same dose of applied polyamines declined anthocyanins content in buckwheat cotyledons.

\section{DISCUSSION}

AOA in hypocotyls of etiolated buckwheat seedlings caused reducing accumulation of anthocyanins in comparison to untreated control sample due to inhibitory effect of AOA on PAL actvity (Table 1). PAL catalyzes the first reaction in plant phenylpropanoid metabolism, the elimination of ammonia from L-phenylalanine forming trans-cinnamic acid (Strack 1997). The results of our investigation confirm data obtained by Amrhein (1979). Similar results were also obtained for AOA treatment of three-day-old soybean seedlings (Hoagland and Duke 1982). Another PAL inhibitor, L- $\alpha$-aminooxy- $\beta$-phenyl propionic acid, caused similar to AOA effect - marked accumulation of L-phenylalanine, what suggest decline of its transformation into trans-cinnamic acid (Amrhein and Gödeke 1977; Amrhein and Holländer 1979; Havir 1981).
AOA also declined the content of chlorophylls $a$ and $b$, as well as the content of total carotenoids in buckwheat cotyledons. Similar results were obtained by for soybean seedlings by Hoagland and Duke (1982). The results indicate that AOA has wide influence on plants, and inhibits not only phenylpropanoids biosynthesis but also basic physiological processes, such as photosynthesis.

According to Craker et al. (1971) and Cracker and Wetherbee (1973) ethylene enhanced the biosynthesis of light-induced anthocyanins in plants. Therefore we expected similar results in buckwheat seedlings, but our results do not fully confirm data presented by mentioned authors. During our experiments ethylene caused slight, significant in high concentration of the hormone only, stimulatory effect on anthocyanins accumulation in buckwheat hypocotyls, but in case of cotyledons clear decline of its content was noted (Table 2).

In apple fruits the accumulation of anthocyanins in apple skin is stimulated by ethylene and delayed by inhibitor of ethylene production (Awad and de Jager 2002; Faragher and Brohier 1984; Whale and Singh 2007). Our results indicate that activity of ethylene in buckwheat hypocotyls is relatively small. Moreover, the results obtained for cotyledons suggest that there are various mechanisms of AOA influence on anthocyanins formation in both studied buckwheat tissues. The function of anthocyanins in plants remains not fully understood, and several hypotheses describe their possible role. For example, anthocyanins in the lower epidermal layer of leaves have been postulated to increase light capture by reflecting the transmissible red light back to chloroplast-rich layers (Lee et al. 1979; Lee and Graham 1986). In fact, in our studies anthocyanins were accumulated mainly in lower epidermis of buckwheat cotyledons.

PAs are synthesized from arginine and ornithine by respective decarboxylases. The intermediate agmatine, synthesized from arginine, is converted to Put, which is further transformed to Spd and Spm by transfers of aminopropyl groups from decarboxylated $S$-adenosylmethionine (SAM). SAM is also precursor for ethylene synthesis (Martin-Tanguy 2001). On the other hand, the elevated level of free polyamines may be responsible for the reduction in ethylene production (Apelbaum et al. 1981). Both examined buckwheat tissues have various concentrations of the amines: putrescine, spermidine, cadaverine and tryptamine which indicate different their role in the hypocotyls and cotyledons (Table 3). AOA significantly stimulated synthesis of putrescine in hypocotyls, but clearly declined its level in buckwheat cotyledons. The increase of putrescine in hypocotyls is difficult to explain. Probably the increase is stress response caused by AOA. The phenomenon shows the importance of polyamines for plant survival (Bais and Ravishankar 2002; Kakkar and Sawhney 2002; Kusano et al. 2008; Liu et al. 2007).

AOA caused declining of putrescine in cotyledons was associated with enhancing of spermidine content (Table 3). Putrescine is a substrate for synthesis of spermidine, catalyzed by spermidine synthase and used aminopropyl groups from the SAM (Martin-Tanguy 2001). Obtained by us data partly confirm results obtained during studies of cut carnation flowers, in which AOA inhibited ethylene production and caused increased the level of spermine (Roberts et al. 1984). 
AOA substantially declined the level of cadaverine in buckwheat cotyledons, and did not affect its content in hypocotyls (Table 3). According to Icekson et al. (1986), in etiolated pea seedlings treated with ethylene the level of cadaverine increased. In our experiments AOA caused the decline of cadaverine in buckwheat cotyledons, probably due to inhibition of ethylene synthesis. However in case of hypocotyls AOA had no affect on cadaverine content, and therefore our results partly support the mentioned Icekson et al. (1986) hypothesis, regarding role of ethylene in cadaverine biosynthesis. Tryptamine was found in very low concentration or in traces in buckwheat tissues, and its level was not changed as a result of AOA treatment.

It was found earlier that polyamines inhibited ethylene biosynthesis in apple fruit and tobacco leaves (Apelbaum et al. 1981). It means that exogenously used polyamines can increase accumulation anthocyanins. However results shown in Table 4 indicate that applied polyamines (spermidine, putrescine) only slightly enhanced the level of anthocyanins in buckwheat hypocotyls, and diminished its content in cotyledons. It suggests that the mechanism is not so simple, or there are various mechanisms of PAs influence on anthocyanins. The reason can be also their various roles of the PAs in particular plant tissues. While ethylene action is associated with senescence and ripening, PAs can be considered as senescence inhibitors.

In general, our results indicate that the effect of AOA on accumulation of polyamines strongly depends on examined tissues and the amine investigated. Different effect of AOA on polyamines and anthocyanins metabolism in buckwheat hypocotyls and cotyledons, suggest that there no exists one mechanism of the influence in buckwheat seedlings. It also indicates on different physiological roles of anthocyanins and polyamines in buckwheat hypocotyls and cotyledons.

\section{LITERATURE CITED}

AMRHEIN N. 1979. Biosynthesis of cyanidin in buckwheat hypocotyls. Phytochemistry 18: 585-589.

AMRHEIN N., GÖDEKE K.H. 1977. $\alpha$-Aminooxy- $\beta$-phenylpropionic acid a potent inhibitor of L-phenylalanine ammonialyase in vitro and in vivo. Plant Sci. Lett. 8: 313-317.

AMRHEIN N. HOLLÄNDER H. 1979. Inhibition of anthocyanin formation in seedlings and flowers by the enantiomers of L- $\alpha$ -aminooxy- $\beta$-phenylpropionic acid and their N-benzyloxycarbonyl dervivatives. Planta 144: 385-389.

AMRHEIN N., WENKER D. 1979. Novel inhibitors of ethylene production in higher plants Plant Cell Physiol. 20: 1635-1642.

APELBAUM A., BURGOON A.C., ANDERSON J.D., LIEBERMAN M., BEN-ARIE R., MATTOO A.K. 1981. Polyamines inhibit biosynthesis of ethylene in higher plant tissue and fruit protoplasts. Plant Physiol. 68: 453-456.

AWAD M.A., DE JAGER A. 2002. Formation of flavonoids, especially anthocyanin and chlorogenic acid in 'Jonagold' apple skin: influences of growth regulators and fruit maturity. Sci. Hort. 93: 257-266.

BAIS H.P., RAVISHANKAR G.A. 2002. Role of polyamines in the ontogeny of plants and their biotechnological applications. Plant Cell, Tiss. Organ Cult. 69: 1-34.

BOLLER T., HERNER R.C., KENDE H. 1979. Assay for and enzymatic formation of an ethylene precursor, 1-aminocyclopropane-1-carboxylic acid. Planta 145: 293-303.

CHANDRAN S., ZULIANA R., YIP Y.K., NAIR H., NASRULHAQ B.A., TIEW Y.N. 2007. Effects of sugars and aminooxy- acetic acid on the longevity of pollinated Oncidium gower ramsey flowers. Malay. J. Sci. 26: 57-63.

COHEN E., ARAD S.M., HEIMER Y.H., MIZRAHI Y. 1984. Polyamine biosynthetic enzymes in the cell cycle of Chlorella. Plant Physiol. 74: 385-388.

CRAKER L.E., STANDLEY L.A., STARBUCK M.J. 1971. Ethylene control of anthocyanin synthesis in sorghum. Plant Physiol. 48: 349-352.

CRAKER L.E., WETHERBEE P.J. 1973. Ethylene, carbon dioxide, and anthocyanin synthesis. Plant Physiol. 52: 177-179.

ENGELSMA G. VAN BRUGGEN J.M.H. 1971. Ethylene production and enzyme induction in excised plant tissues. Plant Physiol. 48: 94-96.

FARAGHER J.D., BROHIER R.L. 1984. Anthocyanin accumulation in apple skin during ripening: regulation by ethylene and phenylalanine ammonia-lyase. Sci. Hort. 22: 89-96.

FLORES H.E., GALSTON A.W. 1982. Analysis of polyamines in higher plants by high performance liquid chromatography. Plant Physiol. 69: 701-706.

HANDA A.K., MATTOO A.K. 2010. Differential and functional interactions emphasize the multiple roles of polyamines in plants. Plant Physiol. Biochem. 48: 540-546.

HAVIR E. 1981. Modification of L-phenylalanine ammonia-lyase in soybean cell suspension cultures by 2-aminooxyacetate and L-2-aminooxy-3-phenylpropionate. Planta 152: 124-130.

HOAGLAND R.E., DUKE O.S. 1982. Effects of glyphosate on metabolism of phenolic compounds VIII. Comparison of the effects of aminooxyacetate and glyphosate. Plant Cell Physiol. 23: 1081-1088.

HONG S.J., LEE S.K. 1996. Changes in endogenous putrescine and the relationship to the ripening of tomato fruits. J. Korean Soc. Hort. Sci. 37: 369-373.

HORBOWICZ M., BRENAC P., OBENDORF R.L. 1998. Fagopyritol B1, O- $\alpha$-D-galactopyranosyl-( $1 \rightarrow 2)$-D-chiro-inositol, a galactosyl cyclitol in maturing buckwheat seeds associated with dessication tolerance. Planta 205: 1-11.

HORBOWICZ M., GRZESIUK A., DĘBSKI H., KOCZKODAJ D., SANIEWSKI M. 2008. Methyl jasmonate inhibits anthocyanins synthesis in seedlings of common buckwheat (Fagopyrum esculentum Moench). Acta Biol. Crac. Ser. Bot. 50: 71$-78$.

HORBOWICZ M., MIODUSZEWSKA H., KOCZKODAJ D., SANIEWSKI M. 2009. The effect of cis-jasmone, jasmonic acid and methyl jasmonate on accumulation of anthocyanins and procyanidins in seedlings of common buckwheat (Fagopyrum esculentum Moench). Acta Soc. Bot. Pol. 78: 271-277.

HORBOWICZ M., OBENDORF R.L. 2005. Fagopyritols accumulation and germination of buckwheat seeds matured at 15 , 22, or $30^{\circ} \mathrm{C}$. Crop Sci. 45: 1264-1270.

HYODO H., HASHIMOTO C., MOROZUMI S., UKAI M., YAMADA C. 1993. Induction of ethylene production and lignin formation in wounded mesocarp tissue of Cucurbita maxima. Acta Hort. 343: 264-269.

ICEKSON I., BAKHANSHVILI M., APELABUM A. 1986. Inhibition by ethylene of polyamine biosynthetic enzymes, enhanced lysine decarboxylase activity and cadaverine accumulation in pea seedlings. Plant Physiol. 82: 607-609.

KAKKAR R.K., SAWHNEY V.K. 2002. Polyamine research in plants - a changing perspective. Physiol. Plant. 116: 281-292.

KAWA J.M., TAYLOR C.G., PRZYBYLSKI R. 2003. Buckwheat concentrate reduces serum glucose in streptozotocin-diabetic rats. J. Agric. Food Chem. 51: 7287-7291.

KIM S.-J., KAWAHARADA C., SUZUKI T., SAITO K., HASHIMOTO N., TAKIGAWA S., NODA T., MATSUURAENDO C.,YAMAUCHI H. 2006. Effect of natural light periods on rutin, free amino acid and vitamin $\mathrm{C}$ contents in the sprouts of common (Fagopyrum esculentum Moench) and tartary (F. tataricum Gaertn.) buckwheats. Food Sci. Technol. Res. 12: 199-205. 
KIM S.-L., KIM S.-K., PARK C.-H. 2004. Introduction and nutritional evaluation of buckwheat sprouts as a new vegetable. Food Res. Int. 37: 319-327.

KUMAR A., ALTABELLA T., TAYLOR M., TIBURCIO A.F. 1997. Recent advances in polyamine research. Trends Plant Sci. 2: 124-130.

KUSANO T., BERBERICH T., TATEDA C., TAKAHASHI Y. 2008. Polyamines: essential factors for growth and survival. Planta 228: 367-381

LEE D.W., LOWRY J.B., STONE B.C. 1979. Abaxial anthocyanin layer in leaves of tropical rain forest plants: Enhancer of light capture in deep shade. Biotropica 11: 70-77.

LEE D.W., GRAHAM R. 1986. Leaf optical properties of rainforest sun and shade extreme shade plants. Am. J. Bot. 73: 1100-1108.

LICHTENTHALER H.K., WELBURN A.R. 1983. Determination of total carotenoids and chlorophyll a and $\mathrm{b}$ of leaf extracts in different solvents. Biochem. Soc. Trans. 603: 591-592.

LIU J.-H., KITASHIBA H., WANG J., BAN Y., MORIGUCHI T. 2007. Polyamines and their ability to provide environmental stress tolerance to plants. Plant Biotech. 24: 117-126.

LOCKE J.M., BRYCE J.H., MORIS P.C. 2000. Contrasting effects of ethylene perception and biosynthesis inhibitors on germination and seedling growth of barley (Hordeum vulgare L.). J. Exp. Bot. 352: 1843-1849.

MANCINELLI A.L. 1984. Photoregulation of anthocyanin synthesis. VIII. Effects of light pretreatments. Plant Physiol. 75: 447-453.
MARTIN-TANGUY J. 2001. Metabolism and function of polyamines in plants: Recent development (new approaches). Plant Growth Regul. 34: 135-148.

ROBERTS D.R., WALKER M.A., THOMPSON J.E., DUMBROFF E.B. 1984. The effects of inhibitors of polyamine and ethylene biosynthesis on senescence, ethylene production and polyamine levels in cut carnation flowers. Plant Cell Physiol. 25: $315-322$.

SERRANO M., ROMOJARO F., CASAS J.L., ACOSTA M. 1991. Ethylene and polyamine metabolism in climacteric and non-climacteric carnation flowers. HortScience 26: 894-896.

STRACK D. 1997. Phenolic metabolism. In: P.M. Dey, J.B. Harborne (eds), Plant Biochemistry. Academic Press Incorporated, New York, pp. 387-416.

TAKAHASHI T., KAKEHI J.-I. 2010. Polyamines: ubiquitous polycations with unique roles in growth and stress responses. Ann. Bot. 105: 1-6.

TROYER J.R. 1964. Anthocyanin formation in excised segments of buckwheat-seedling hypocotyls. Plant Physiol. 39: 907-912.

WALTERS D.R. 2003. Polyamines in plant disease. Phytochemistry 64: 97-107.

WHALE S.K., SINGH Z. 2007. Endogenous ethylene and color development in the skin of 'Pink Lady' apple. J. Am. Soc. Hort. Sci. 132: 20-28. 